\title{
XIV.
}

\section{Beiträge zur Kenntniss der Sputa.}

\author{
Von Prof. Dr. N. Friedreich in Heidelberg.
}

(Hierzu Taf. XIII.)

\section{Wahrer Knochen im Auswurf.}

$E_{s}$ ist auffallend, dass, wenn wir die Fälle der von Aussen als Fremdkörper aspirirten und wieder ausgehusteten Knochenstücke ausschljessen, von den Autoren nirgends des Vorkommens wirklicher Knochenpartikel im Auswurf Erwähnung geschieht; selbst in der sonst so vollständigen und vortrefflichen Abhandlung von Biermer (die Lehre vom Auswurf, Würzburg 1855) finden sich hierüber keine Andeutungen. Nicht selten wohl beobachtet man im Verlaufe chronischer ulcerativer Prozesse des Lungenparenchyms in den Sputis grössere und kleinere Kalkconcremente (Phthisis calculosa der älteren Autoren), welche meist Theile verkalkter käsiger Heerde, verkalkter perforirender Bronchialdrisen, Venensteine u. dgl. darstellen, und welche als amorphe, einfache Incrustationen wesentlich von ächtem Knochengewebe unterschieden werden müssen. Als seltenes Beispiel des Vorkommens wahrer Knochenpartikel im Auswurf, welche kaum anders, denn als Bestandtheile des eigenen Skelettes gedeutet werden konnten, möge nachstehende Beobachtung dienen, die ich bereits im Sommer 1851 zu machen Gelegenheit hatte und iuber welche ich in meinen Notizen Folgendes aufgezeichnet finde.

Phïlipp Dorbath von Rothenfels (Bayern), ein 14jähriger, sehr schwächlicher und gracil gebauter Knabe, gibt an, seit 7 Jahren kyphotiscb geworden zu sein und seit 4 Jahren an einem immer mehr zunehmenden, mit Abnahme der Krăfte und Abmagerung einhergehenden Husten zu leiden. Häufig will Patient mit dem schleimig eiterigen, mitunter blutigen Auswurf grössere und kleinère Knochenstückchen ansgehustet haben. Als Patient im Mai 1851 in das Juliushospital zu Würzburg aufgenommen wurde, bestanden ausserdem nächtliche Schweisse, Durch- 


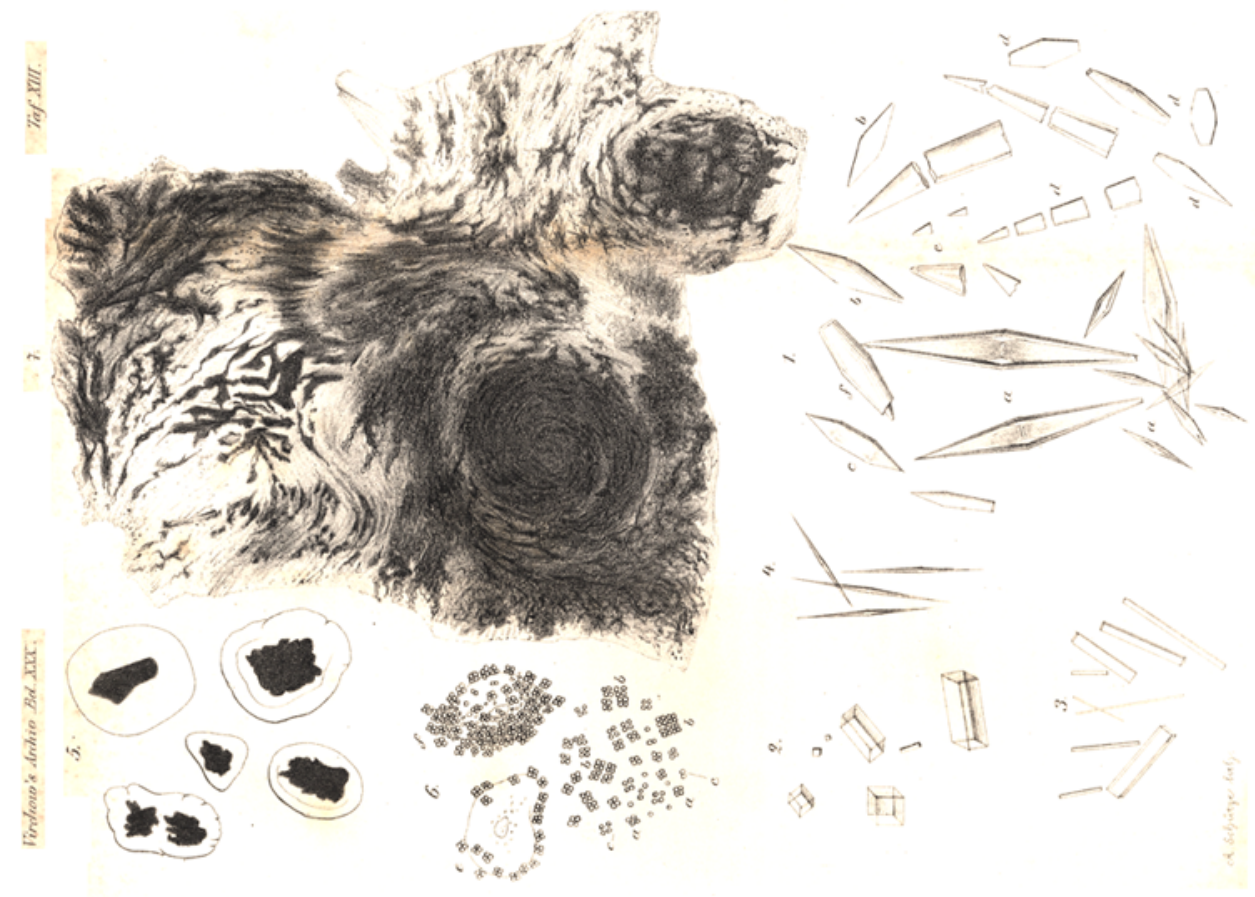


falle, geschwollene Beine und stechende Schmerzen in der rechten oberen Thoraxgegend. Puls über 120 Schläge in der Minute. Die objective Untersucbung zeigte eine bedeutende tellerförmige Vertiefung der rechten Unterschlüsselbeingegend mit geringen respiratorischen Excursionen; Percussionsschall in derselben Ausdehnung gedämpft tympanitísch mit exquisitem Geräusch des gesprungenen Topfs. Von der dritten rechten Rippe bis herab zur Leber leerer Percussionsschall. Die Auscultation zeigt rechts oben und porn starkes bronchiales Athem mit amphorischem Wiederhall und metallisch klingenden Rasselgeräuschen, welche Phänomene sich nach abwärts bis zur Lebergrenze schwächer werdend fortleiten. Rechts hinten oben starke Dämpfung mit leichtem Tympanismus and amphorischer Respiration; weiterhin nach abwärts bis zur Lungengrenze leerer Schall ohne deutliches Respirationsgeräusch. An der linken Lungenspitze vorn und hinten leicbte Dämpfung mit rauhem vesiculärem Athmen und prolongirtem Exspirium; nach abwärts sonore Percussion mit normalem Zellenathmen. Herz normal, ebenso Leber, Milz und Harn. - Am oberen Theile der Wirbelsäule findet sich in Form eines sehr starken Höckers eine kyphotische Hervortreibung des letzten Halswirbels und der vier ersten Brustwirbel, welche bei Druck ziemlich schmerzhaft erscheint. Auch während des Aufenthaltes des Kranken im Hospitale wurden nicht selten, selbst bis erbsengrosse, spongiös-cariöse Knocbenbröckel ausgehustet, deren Natur sofort nicht zweifelhaft sein konnte und in denen das Mikroskop wahre Knochenstructur nachwies.

Obgleich der Kranke nach einigen Wochen seines Aufenthaltes in der Anstalt dieselbe ohne wesentliche Besserung wieder verliess, und somit die Diagnose der Bestätigung durch die Section ermangelte, so schien doch keinem Zweifel zu unterliegen, dass Patient an tuberkulöser" Lungenphthise mit rechtsseitigem chronischem Pleuraerguss gelitten hatte. Der fortschreitende ulcerative Prozess in der rechten Lungenspitze hatte offenbar bis auf die cariösen Wirbelkörper sich fortgesetzt, so dass die letzteren nach hinten und innen einen Theil der Innenfläcbe der Höhle unmittelbar begrenzten, wodurch das Hineingelangen cariöser Knochenfragmente in letztere ermöglicht war. Dass in ähnlicher Weise cariöse oder necrotische Bestandtheile des Sternums, der Clavicula oder der Rippen unter Umständen im Auswurf erscheinen könnten, bedarf nach dem Gesagten wohl keiner weiteren Begründung. 